\title{
Parameter Biologi dan Demografi Parasitoid Diadegma semiclausum Hellen (Hymenoptera : Ichneumonidae) pada Plutella xylostella L. (Lepidoptera : Plutellidae)
}

\author{
NI PUTU NIA KUMARAWATI"), I WAYAN SUPARTHA, DAN \\ KETUT AYU YULIADHI
}

\begin{abstract}
Program Studi Magister Bioteknologi Pertanian Fakultas Pertanian Universitas Udayana J1. PB Sudirman, Denpasar-Bali.

${ }^{*}$ E-mail: d.niakumarawati@gmail.com
\end{abstract}

\begin{abstract}
Biological and Demographic Parameters of Parasitoid Diadegma semiclausum Hellen (Hymenoptera: Ichneumonidae) on Plutella xylostella L. (Lepidoptera: Plutellidae). Diadegma semiclausum Hellen (Hymenoptera: Ichneumonidae) is one of the parasitoid larvae which attacks Plutella xylostella (Lepidoptera: Plutellidae) effectively. This research was aimed to know the biology of parasitoid $D$. semiclausum in broccoli. The research was carried out in a laboratory by observing the development of parasitoid, fecundity, longevity the males and females as well as parameters demographic of $D$. semiclausum. The results showed that immature development time of $D$. semiclausum parasitoid from egg up to adult the imago was 10.65 \pm 0.63 days, with the number of fecundity was 22.9 grains. Longevity of male imago of $D$. semiclausum was $12.10 \pm 0.74$ days and imago of females $9.80 \pm 1.87$ days. Parameters demographic of $D$. semiclausum showed that net reproduction rate $\left(\mathrm{R}_{0}\right)$ was 22.11 per generation, intrinsic growth rate (r) was 0.18 per day, limited increased rate $(\lambda)$ was 1.16 individuals per day, generation time $(\mathrm{T})$ was 17.50 day.
\end{abstract}

Keywords: Biology, parasitoids, Diadegma semiclausum and broccoli

\section{PENDAHULUAN}

Diadegma semiclausum Hellen merupakan parasitoid larva $P$. xylostella yang bersifat soliter. $D$. semiclausum juga merupakan komponen pengendali biologi yang penting untuk hama $P$. xylostella khususnya di dataran tinggi. Apabila $D$. semiclausum memarasit hama $P$. xylostella maka akan mempengaruhi perkembangan serangga inangnya terutama berpengaruh terhadap fisiologi dan perilaku larva $P$. xylostella sehingga parasitoid $D$. semiclausum berperan penting dalam menurunkan populasi serangga inangnya. Menurut Waage dan Cherry (1992) berkurangnya peluang bertahan hidup dan menurunnya jumlah keturunan dari hama $P$. xylostella akibat dari adanya parasitoid $D$. semiclausum. Parasitoid D. semiclausum dikatakan serangga tabuhan yang berwarna 


\section{NI PUTU NIA KUMARAWATI. et al. Parameter Biologi dan Demografi Parasitoid Diadegma...}

hitam dengan panjang tubuh 4,0-5,0 $\mathrm{mm}$. Larva $P$. xylostella yang terparasit oleh $D$. semiclausum terlihat hijau kekuningan dan abdomen tengah membesar, sedangkan saat membentuk pupa yaitu bagian posterior membulat serta pupanya berwarna hitam (Herlinda, 2005).

Keberhasilan

parasitoid

D. semiclausum sudah diketahui di beberapa negara salah satunnya di Tenggara Queensland, Australia yang mana kemampuan parasitisasi D. semiclausum dalam memarasit larva $P$. xylostella mencapai $95 \%$ pada musim dingin dan awal musim semi (Furlong \& Zalucki, 2007). Selain itu, imago betina $D$. semiclausum lebih mudah menyesuaikan diri dalam lokasi inang dan strategi pencarian inang terhadap pertahanan perilaku inangnya, serta $D$. semiclausum lebih efektif dalam mendeteksi dan memparasit inangnya (Wang \& Keller, 2002). P. xylostella merupakan hama yang menyerang tanaman kubis-kubisan (Cruciferae) yaitu salah satunya tanaman brokoli. Hama P. xylostella yang menyerang daun tanaman brokoli yaitu pada stadium larva. Bagi petani dengan adanya hama $P$. xylostella pada tanaman budidayanya sangat membawa dampak pada hasil panen sehingga sebagian besar petani mengendalikan hama tersebut menggunakan insektisida.

Pengendalian larva $P$. xylostella pada umumnya masih mengandalkan insektisida sintetik sehingga dengan pengendalian tersebut setidaknya perlu diubah. Pemahaman tentang tingkat tropik atau rantai makan sebaiknya perlu dipahami agar dapat menjaga maupun menyeimbangkan stabilitas ekosistem yang ada pada lingkungan. Dalam menjaga keseimbangan stabilitas ekosistem, kita harus tahu faktor pembatas yang mempengaruhi kestabilan ekosistem tersebut yaitu kerapatan $P$. xylostella. Faktor pembatas yang terpaut dengan kerapatan yaitu dengan adanya musuh alami. Musuh alami merupakan salah satu komponen pengendalian yang menerapkan pengendalian hama terpadu (PHT). Penerapan PHT tersebut dinilai aman dan menguntungkan karena pengendalian tersebut telah sesuai dengan ekosistem sendirinya di alam.

Pengendalian larva $P$. xylostella dengan memanfaatkan parasitoid $D$. semiclausum mempunyai prospek yang baik ke depan, namun informasi tentang biologi D. semiclausum terutama parameter demografi masih terbatas. Penelitian biologi D. semiclausum dengan mengetahui keperidian, waktu perkembangan telur sampai imago dan lama hidup imago serta parameter demografi parasitoid $D$. semiclausum setidaknya dapat dijadikan acuan sebagai pengendali hayati yang memanfaatkan agen hayati.

\section{METODE PENELITIAN}

Parasitoid D. semiclausum dan inang yang digunakan larva $P$. xylostella berasal dari perbanyakan yang dilakukan di laboratorium Integrated Pest Management (IPM), Fakultas Pertanian, Universitas Udayana.

Percobaan biologi D. semiclausum dilakukan dengan cara satu pot tanaman brokoli yang telah terinfestasi 10 larva $P$. xylostella instar-3 dimasukkan kedalam kotak plastik yang berukuran tinggi $20 \mathrm{~cm}$ dan lebar $12 \mathrm{~cm}$. Selanjutnya diinokulasikan sepasang imago parasitoid D. semiclausum. Setelah 24 jam dilakukan pergantian pot 
tanaman brokoli baru yang telah terinfestasi 10 larva $P$. xylotella instar-3. Pergantian pot tanaman brokoli yang terinfestasi larva $P$. xylostella dilakukan setiap hari hingga imago parasitoid D. semiclausum mati. Masingmasing percobaan diulang 10 kali. Setelah muncul imago parasitoid kemudian dilakukan perhitungan jumlah imago yang muncul dari awal percobaan hingga imago parasitoid mati. Peletakkan telur $D$. semiclausum dari awal meletakkan telur hingga imago mati, maka didapatkan jumlah keperidian parasitoid D. semiclausum. Pengamatan perkembangan telur dan larva dilihat dari peletakkan telur pertama hingga terbentuk pupa, sedangkan pupa dilihat dari pupa terbentuk hingga muncul imago dan lama hidup imago dilihat dari imago muncul hingga imago tersebut mati. Data yang diperoleh ditabulasikan kemudian ditampilkan dalam bentuk tabel.

Parameter demografi parasitoid $D$. semiclausum yang diamati meliputi:laju reproduksi kotor (GRR), laju reproduksi bersih (Ro), laju pertambahan intrinsik (r), rataan lama generasi $(\mathrm{T})$, dan waktu berlipat ganda (DT) Pengamatan demografi dilakukan dengan cara satu pot tanaman brokoli yang telah terinfestasi 10 larva $P$. xylostella instar-3 dimasukkan kedalam kotak plastik yang berukuran tinggi $20 \mathrm{~cm}$ dan lebar $12 \mathrm{~cm}$ kemudian diinokulasikan sepasang imago parasitoid D. semiclausum. Setelah 24 jam dilakukan pergantian pot tanaman brokoli yang baru dan telah terinfestasi 10 larva $P$. xylotella instar-3. Pergantian pot tanaman brokoli yang terinfestasi larva $P$. xylostella dilakukan setiap hari hingga imago parasitoid $D$. semiclausum mati. Masing-masing percobaan diulang 10 kali. Setelah muncul imago parasitoid kemudian dilakukan perhitungan jumlah imago yang muncul dari awal percobaan hingga imago parasitoid mati.

Pengamatan peluang hidup dan keperidian harian dapat ditentukan statistik demografi $D$. semiclausum dengan metode Birch (1984) yaitu dengan menghitung peluang hidup $D$. semiclausum sampai umur $x\left(1_{\mathrm{x}}\right)$ dan rata-rata jumlah keturunan yang dihasilkan per imago pada umur $x\left(\mathrm{~m}_{\mathrm{x}}\right)$ dengan persamaan :

1. Laju reproduksi kotor $(G R R)=\sum m_{x}$

2. Laju reproduksi bersih $\left(\mathrm{R}_{0}\right)=\sum 1_{\mathrm{x}} \cdot \mathrm{m}_{\mathrm{x}}$

3. Rataan satu generasi $(T)=\left(\sum x \cdot 1_{x} \cdot m_{x}\right) / R_{0}$

4. Laju pertumbuhan intrinsik

$\mathrm{r}=\sum 1_{\mathrm{x}} \mathrm{m}_{\mathrm{x}} \mathrm{e}^{-\mathrm{rmx}}=1$

$\mathrm{r}$ awal $=\left(\operatorname{Ln~} \mathrm{R}_{0}\right) / \mathrm{T}$

5. Populasi berlipat ganda $(\mathrm{DT})=\ln (2) / \mathrm{T}$

6. Laju pertambahan terbatas $(\lambda)=\operatorname{anti} \log e^{r}$

HASIL DAN PEMBAHASAN

Lama Perkembangan Pradewasa

Parasitoid D. semiclausum

Keperidian parasitoid D. semiclausum rata-rata 22,9 butir selama hidupnya (Tabel 1). Menurut Abbas (1988) rata-rata imago betina $D$. semiclausum meletakkan telurnya yaitu 13,6 butir per hari dengan kepadatan 20 larva P. xylostella.

Waktu perkembangan $D$. semiclausum dari telur, larva, dan pupa berturut-turut yaitu 1,50 $\pm 0,00$ hari; $3,85 \pm 0,24$ hari; dan 5,30 \pm 0,48 (Tabel 1). Menurut Abbas (1988) periode perkembangan $D$. semiclausum yaitu telur berkisar 38 jam, larva berkisar 5,4 hari dan pupa berkisar 5,9 hari dengan suhu $25^{\circ} \mathrm{C}$. Rata-rata perkembangan $D$. semiclausum dari telur hingga imago berkisar 10,65 $\pm 0,63$ hari. Larva $D$. semiclausum terlihat berwarna 


\section{NI PUTU NIA KUMARAWATI. et al. Parameter Biologi dan Demografi Parasitoid Diadegma...}

transparan. Pupa D. semiclausum menyerupai tabung berwarna abu-abu semakin lama akan berwarna kehitaman. Menurut Lee et al. (1995) bahwa periode perkembangan $D$. semiclausum dari telur sampai imago yaitu berturut-turut 21,$5 ; 21,1 ; 16,6$ dan 13,3 hari pada suhu masing-masing $20^{\circ} \mathrm{C}, 22^{\circ} \mathrm{C}, 25^{\circ} \mathrm{C}$ dan $28^{0} \mathrm{C}$.

Tabel 1. Biologi parasitoid D. semiclausum dengan suhu $29^{\circ} \mathrm{C}$ pada ketinggian tempat $<500$ meter diatas permukaan laut

\begin{tabular}{ccc}
\hline Fase perkembangan & $\begin{array}{c}\text { D. semiclausum } \\
\text { Rataan } \pm \text { galat }\end{array}$ & Satuan \\
\hline Telur & $1,50 \pm 0,00$ & hari \\
Larva & $3,85 \pm 0.24$ & hari \\
Pupa & $5,30 \pm 0,48$ & hari \\
Keseluruhan pradewasa & $10,65 \pm 0,63$ & hari \\
Lama hidup imago betina & $9,80 \pm 1,87$ & hari \\
Lama hidup imago jantan & $12,10 \pm 0,74$ & hari \\
\hline
\end{tabular}

Lama hidup imago jantan lebih panjang dibandingkan lama hidup imago betina. Lama hidup imago betina yaitu 9,80 $\pm 1,874$ hari dan lama hidup imago jantan yaitu 12,10 $\pm 0,738$ hari (Tabel 1). Waktu yang dibutuhkan D. semiclasusum untuk perkembangan pradewasa menunjukkan kemampuan berkembang pada setiap fase dalam keadaan nutrisi inang yang tersedia. Ketersediaan nutrisi pada inang sangat berpengaruh terhadap perkembangan parasitoid itu sendiri (Godfray, 1994). Hasil perkembangan pradewasa menunjukkan rentang waktu yang dibutuhkan parasitoid $D$. semiclausum selama satu generasinya. Informasi rentang waktu perkembangan parasitoid sangat penting diketahui karena informasi tersebut akan berhubungan dengan perbanyakan $D$. semiclausum di laboratorium dan pelepasan parasitoid D. semiclausum di lapang.

Keunggulan parasitoid D. semiclausum dalam menangani inang terlihat lebih cepat merespon atau mengenali inang larva $P$. xylostella dibandingkan dengan $C$. plutellae.
Pernyataan tersebut juga didukung Wang \& Keller (2002) yang mengatakan bahwa imago betina $D$. semiclausum lebih mudah menyesuaikan diri dalam lokasi inang dan strategi pencarian inang terhadap pertahanan perilaku inangnya, serta $D$. semiclausum lebih efektif dalam mendeteksi dan memparasit inangnya daripada parasitoid $C$. plutellae.

\section{Parameter Demografi D. semiclausum}

Parameter demografi (life table) yang dihitung dari data peluang hidup (lx) dan keperidian $(\mathrm{mx})$, diperoleh laju reproduksi kotor (GRR), laju reproduksi bersih (Ro), laju pertambahan intrinsik $\left(\mathrm{r}_{\mathrm{m}}\right)$, rataan lama generasi (T), waktu berlipat ganda (DT) dan laju pertambahan terbatas $(\lambda)$ yang disajikan dalam Tabel 2. Parasitoid D. semiclausum mempunyai nilai laju reproduksi kotor (GRR) sebesar 22,4 menunjukkan bahwa $D$. semiclausun mampu menghasilkan keturunan sebesar 22 individu/induk/generasi.

Nilai laju reproduksi bersih (Ro) $D$. semiclausum sebesar 22,11 (Tabel 2). Nilai 
tersebut memperlihatkan bahwa keturunan $D$. semiclausum yang dihasilkan oleh seekor imago betina yaitu 22,11/generasi atau yang artinya populasi $D$. semiclausum berlipat ganda 22,11 kali setiap generasinya. Populasi D. semiclausum akan berkembang dengan cepat apabila memiliki nilai Ro $>1$, berkurang jika $\mathrm{R}_{0}<1$ dan stabil bila $\mathrm{R}_{0}=1$
(Price, 1997). Sulaeha et. al. (2009) melaporkan nilai laju reproduksi bersih $\left(\mathrm{R}_{0}\right)$ parasitoid Hemiptarsenus varicornis pada Liriomyza huidobrensis yaitu 18,021 yang artinya banyaknya keturunan betina yang dihasilkan oleh seekor imago betina/induk/generasi.

Tabel 2. Statistik demografi $D$. semiclausum suhu $29^{\circ} \mathrm{C}$ pada ketinggian tempat $<500$ meter diatas permukaan laut

\begin{tabular}{clcc}
\hline No & \multicolumn{1}{c}{ Parameter } & Rataan & Satuan \\
\hline 1 & Laju reproduksi kotor $(\mathrm{GRR})$ & 22,4 & individu/induk/generasi \\
2 & Laju reproduksi bersih $\left(\mathrm{R}_{0}\right)$ & 22,11 & kali tiap generasi \\
5 & Rataan lama generasi $(\mathrm{T})$ & 17,50 & hari \\
3 & Laju pertumbuhan intrinsik $(\mathrm{r})$ & 0,18 & ekor/hari \\
4 & Laju pertambahan terbatas $(\lambda)$ & 1,16 & kali lipat/hari \\
6 & Doubling time $(\mathrm{DT})$ & 3,92 & hari \\
\hline
\end{tabular}

Lama waktu satu generasi (T) D. semiclausum yaitu berkisar 17,50 hari (Tabel 1.2). Nilai tersebut menunjukkan rata-rata waktu satu generasi dari D. semiclausum. Selain itu, nilai $\mathrm{T}$ berarti dalam waktu kurang lebih dua minggu (17,50 hari) imago betina D. semiclausum yang muncul mampu menghasilkan keturunannya kembali.

Nilai $\mathrm{r}_{\mathrm{m}}$ D. semclausum adalah sebesar 0,18/hari. Nilai $r$ diartikan sebagai nilai konstanta untuk sutu kondisi yang konstan. Suatu spesies dapat bertahan hidup pada suatu lingkungan maka nilai $\mathrm{r}$ dari spesies tersebut harus dilampaui atau lebih tinggi. Apabila nilai $r$ kurang, maka spesies tersebut gagal untuk mempertahankan hidupnya. Walaupun demikian, apabila nilai $r$ makin tinggi tidak berarti juga spesies tersebut dapat bertahan hidup (Birch, 1948). Nilai $r$ awal diperoleh $\mathrm{r}=\ln \mathrm{R}_{0} / \mathrm{T}=3,10 / 17,50=$ 0,18 . Setelah diperoleh nilai $\mathrm{r}$ maka laju pertambahan terbatas $(\lambda)$ diperoleh 1,16 kali lipat/hari. Nilai laju pertambahan terbatas menunjukkan kelipatan pertambahan populasi D. semiclausum per hari. Nilai DT (Doublingtime) D. semiclausum yaitu waktu yang dibutuhkan $D$. semiclausum untuk menjadi berlipat ganda yaitu 3,92 hari. Nilai DT yang tinggi akan mempengaruhi peningkatan laju reproduksi kotor dan nilai laju reproduksi bersih dalam suatu waktu tertentu.

Peluang hidup D. semiclausum digambarkan dalam bentuk kurva kesintasan dan keperidian. Sintasan atau peluang hidup D. semiclausum diperoleh dari pengamatan harian dari peletakkan telur hingga menjadi imago. Kurva sintasan D. semiclausum menunjukkan peluang hidup mulai menurun sejak individu berumur 21 hari (Gambar 1). Kurva peluang hidup $D$. semiclausum memperlihatkan pola tipe I yaitu kematian 


\section{NI PUTU NIA KUMARAWATI. et al. Parameter Biologi dan Demografi Parasitoid Diadegma...}

populasi $D$. semiclausum banyak terjadi pada individu dewasa (imago) yang memasuki tahap akhir perkembangan.

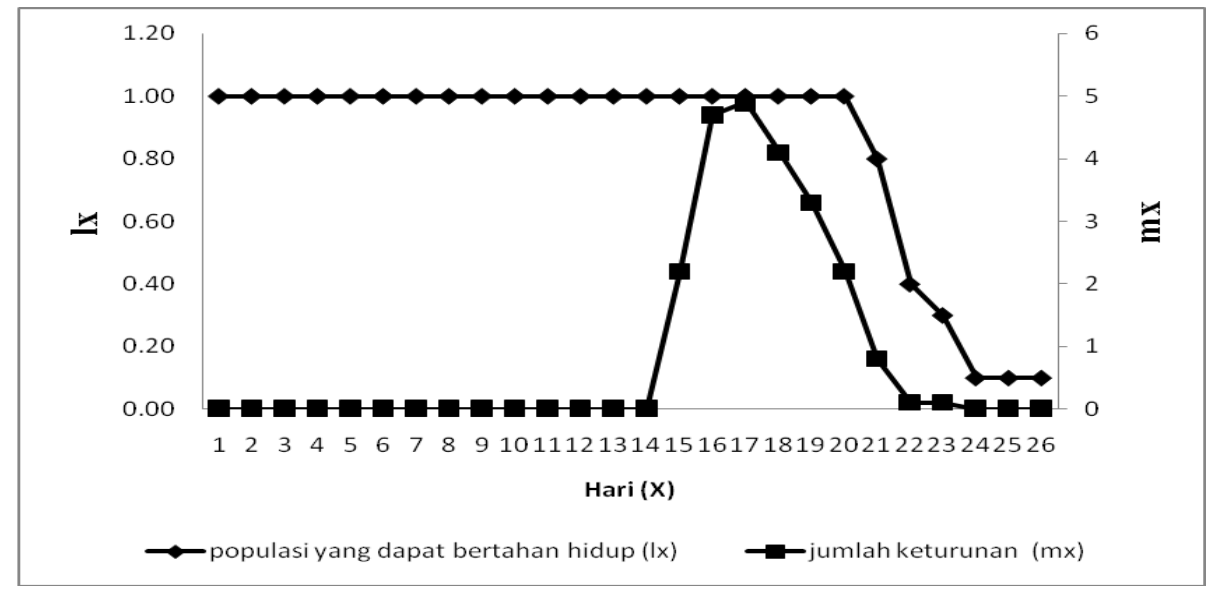

Gambar 1. Kurva peluang hidup $\left(\mathrm{l}_{\mathrm{x}}\right)$ dan keperidian $\left(\mathrm{m}_{\mathrm{x}}\right)$ D. semiclausum

Dilihat dari neraca kehidupan (life table) D. semiclausum belum banyak dilaporkan sehingga neraca kehidupan sangat bermanfaat sebagai gambaran perubahanperubahan yang terjadi dalam satu populasi selama satu generasi (Price, 1975). Pengetahuan mengenai neraca kehidupan parasitoid D. semiclausum merupakan salah satu langkah awal dalam mempelajari perkembangan populasi $D$. semiclausum. Berdasarkan penelitian yang telah dilakukan, banyak hal yang dapat berpengaruh terhadap perkembangan dan sintasan D. semiclausum saat penelitian. Menurut Morgan et al. (2001) bahwa faktor-faktor yang berpengaruh terhadap neraca kehidupan yaitu spesies, inang, kondisi iklim tempat penelitian dan metode perbanyakan serangga (rearing) yang digunakan. Kurva sintasan D. semiclausum menunjukkan peluang hidup yang tinggi pada awal perkembangan kemudian menurun secara perlahan seiring dengan bertambahnya umur parasitoid.Bentuk kurva kesintasan perlu diketahui agar kita dapat memahami strategi reproduksi suatu populasi serangga (Price, 1984). Neraca kehidupan penting diamati untuk mengetahui tingkat kesesuaian tanaman inang dengan serangganya (Birch, 1948).

\section{SIMPULAN}

Waktu perkembangan D. semiclausum menunjukkan rata-rata yang dibutuhkan parasitoid dari telur sampai muncul imago berkisar 10,65 hari. Lama hidup imago jantan lebih panjang dibandingkan lama hidup imago betina. Dari parameter demografi $D$. semiclausum menunjukkan parasitoid dapat dimanfaatkan untuk pengaturan populasi larva $P$. xylostella. Penggunaan musuh alami seperti parasitoid D. semiclusum sangat diperlukan di lapang untuk mengurangi penggunaan insektisida yang berlebihan. Oleh karena itu diperlukan strategi untuk 
pengendalian hayati tersebut agar efektif di lapang.

\section{DAFTAR PUSTAKA}

Abbas M.S.T. 1988. Biological and ecological studies on Diadegma semiclausum Hellen (Hym., Ichneumonidae), a larval parasite of the diamond-back moth, Plutella xylostella (L.) (Lep., Plutellidae) in Egypt. Anzeiger fur Schadlingskunde, Pflanzenschutz, Umweltschutz 61: 1-2.

Birch, L.C. 1948. The intrinsic rate of natural increase of an insect population. $J$. Anim. Ecol. 17: 15-26

Furlong, M.J. and Zalucki, M.P. 2007. Parasitoid complex of diamondback moth in south-east Queensland: first records of Oomyzus sokolowskii (Hymenoptera : Eulophidae) in Australia. Australian Journal of Entomology 46: 167-175

Godfray, HCJ. 1994. Parasitoids : Behavioral and Evolutionary Ecology. New Jersey : Princeton University Press.

Herlinda, S. 2005. Parasitoid dan Parasitisasi Plutella xylostella (L.) (Lepidoptera : Yponomeutidae ) di Sumatera Selatan. Hayati, hlm 151 - 156

Lee S.G., Yoo J.K., Lee J.O. and Hwang C.Y. 1995. The biological characteristics and DBM density suppression effect of Diadegma semiclausum Hellen. RDA Journal of Agricultural Science 37: 329-333

Morgan D, Walters KFA, \& Aegerter JN. 2001. Effect of temperature and cultivar on pea aphid, Acyrthosiphon pisum (Hemiptera: Aphididae) life history. Bull. Entomol. Res. 91(1): 47 52

Price, P.W. 1997. Insect Ecology. Third Ed. John Wiley \& Sons, Inc. New York.

Stireman, JO. 2002. Host location and selection cues in a generalist tachinid parasitoid. Entomologia Experimentalis et Applicata. 103: 23-24.

Sulaeha, Aunu Rauf dan Nina Maryana. 2009. Parameter demografi parasitoid Hemiptarsenus varicornis (Girault) (Hymenoptera : Eulophidae) pada lalat pengorok daun Liriomyza huidobrensis (Diptera : Agromyzidae). J. HPT Tropika Vol. 9. No. 1:8-14

Waage J., and A. Cherry. 1992. Quantifying the impact of parasitoids on diamondback moth. In Diamonback Moth and Other Crucifer Pests, Proc. Second Int. Workshop (N. S. Talekar, Ed.), pp. 245-252. AVRDC, Taiwan.

Wang X.G. and Keller M.A. 2002. A comparison of the host-searching efficiency of two larval parasitoids of Plutella xylostella.Ecological Entomology 27: 105-114. 